\title{
Photocatalytic Treatment of Rhodamine 6G in Wastewater Using Photoactive ZnO
}

\author{
Doina Lutic, ${ }^{1}$ Cristina Coromelci-Pastravanu, ${ }^{1}$ Igor Cretescu, ${ }^{2}$ \\ Ioannis Poulios, ${ }^{3}$ and Catalina-Daniela $\operatorname{Stan}^{4}$ \\ ${ }^{1}$ Department of Materials Chemistry, Alexandru Ioan Cuza University, 11 Carol I Boulevard, 700506 Iași, Romania \\ ${ }^{2}$ Department of Environmental Engineering and Management, Faculty of Chemical Engineering and Environmental Protection, \\ Gheorghe Asachi Technical University of Iasi, 73 Professor D. Mangeron Street, 700050 Iaşi, Romania \\ ${ }^{3}$ Department of Chemistry, Aristotle University of Thessaloniki, 54124 Thessaloniki, Greece \\ ${ }^{4}$ Department of Drug Industry and Pharmaceutical Biotechnology, Grigore T. Popa University of Medicine and Pharmacy, \\ 16 Universitatii Street, 700115 Iaşi, Romania
}

Correspondence should be addressed to Igor Cretescu, icre@tuiasi.ro

Received 27 July 2012; Accepted 22 October 2012

Academic Editor: Christos Trapalis

Copyright (c) 2012 Doina Lutic et al. This is an open access article distributed under the Creative Commons Attribution License, which permits unrestricted use, distribution, and reproduction in any medium, provided the original work is properly cited.

\begin{abstract}
The photocatalytic activity of zinc oxide, prepared by precipitation followed by calcination, was tested using rhodamine $6 \mathrm{G}$ as a rebel organic compound. The experiments were planned in order to allow an optimization procedure, by investigating the effects of different parameters such as the preparative method of the solid, amount of photocatalyst, $\mathrm{pH}$ of the reaction medium, and initial concentration of the dye. The results were compared with those obtained on P-25 Titania, and one of the samples had similar performances in terms of dye degradation degree, but needed higher $\mathrm{pH}$ values to prevent the photocatalyst degradation.
\end{abstract}

\section{Introduction}

The interest for the photocatalytic degradation of different refractory organics present in wastewaters, such as dyes, drugs, and pesticides, comes from the relatively simple procedure and somehow easy-to-set practical setup. The photocatalytic reactions occur in conditions somehow similar to heterogeneous catalysis, involving the simultaneous adsorption of the organic reactant species and oxygen on solid, followed by the oxidation on the surface. The photoactive solid is a semiconductive oxide able to capture the energy for the reaction from photons. The photocatalyst must therefore adsorb simultaneously significant amounts of oxygen and reducing species (organic molecules). A performant photocatalyst is expected to offer adsorption sites for the organics, meaning that a high specific surface area and/or open pore structure are welcome. A very important feature of the photocatalysis is that the reaction can occur at temperature values close to ambient; therefore, the photoreactions are "greener," since the thermal energy is expensive and, most often, its production is pollutant [1-4].
The most intensively species used as photocatalyst is the titanium dioxide in the anatas form; due to its $3.2 \mathrm{eV}$ band gap, it is able to capture the energy even from solar light, widely available, green, and costless. Current research is however devoted to investigate the behavior of other oxidic species such as $\mathrm{ZnO}, \mathrm{WO}_{3}, \mathrm{Fe}_{2} \mathrm{O}_{3}, \mathrm{SnO}_{2}$, and combinations thereof as photocatalysts [5-9].

Rhodamine 6G (R_6G) is a chemically stable organic dye, used often as a tracer to allow finding the transport direction and flow rate of water courses. Other applications concern the biotechnology (such as fluorescence microscopy and fluorescence correlation spectroscopy), and the biochemistry laboratories (as a diagnostic tool in medicine and plant pathology for the enzyme-linked immunosorbent assay (ELISA), to detect the presence of a substance, usually an antigen, in a liquid sample or wet sample). Due to its high stability, it is interesting to find photocatalytic systems able to decompose R_6G to smaller biodegradable species or eventually mineralize it. There are quite many papers in the literature dealing with the photocatalytic degradation of several rhodamines, especially rhodamine B [10-16]. 
The aim of the present work was to synthesize photocatalytically active zinc oxide (band gap around $3.3 \mathrm{eV}$ [17]) and test it in the R_6G photodegradation. We investigated the influence of several operation parameters on the dye removal performance: the initial dye concentration, the $\mathrm{pH}$ value, and the photocatalyst concentration in the reaction medium. This study aims to investigate the properties of $\mathrm{ZnO}$ prepared in a very simple way in the photocatalytic degradation of a rebel test molecule, without investigating the degradation mechanism. The results will be used for comparisons with other transition metal oxides in the future studies.

\section{Experimental Setup}

The zinc oxide was prepared by precipitation as zinc hydroxide, followed by calcination. Zinc nitrate was used as precursor, due to its easy thermal decomposition in the target compound, if traces of the initial salt remain in the precipitate. Two precipitation agents were used, $\mathrm{NaOH}$ and urea.

The precipitation with $\mathrm{NaOH}$ was performed at room temperature, by the simultaneous pouring of zinc nitrate and $\mathrm{NaOH}$ solutions under continuous magnetic stirring in a beaker, while monitored by a Hanna HI 991003 pH-meter, to help keeping the $\mathrm{pH}$ value at 9. The achievement of the complete precipitation degree occurred by heating the slurry at $353 \mathrm{~K}$ for 16 hours.

The precipitation in the presence of urea was performed using a 5/1 molar ratio urea/Zn, by mixing the zinc nitrate solution with urea solution, at a concentration of zinc of about 0.25 moles $\mathrm{L}^{-1}$ in the final solution mixture. This solution was stirred at $363 \mathrm{~K}$ for $14 \mathrm{~h}$ under reflux; the final $\mathrm{pH}$ settled at 7 . In the case of urea, the settlement of a basic $\mathrm{pH}$ value necessary for the precipitation is slowly obtained, due to the thermal decomposition of urea in ammonia and carbon dioxide. This procedure allows obtaining solids with special textures and superficial properties $[18,19]$, due to the slow formation of the crystal nuclei in the precipitation medium. The method is widely used in the synthesis of layered oxide structures and offers the possibility to obtain particles with a lower agglomeration degree and a more ordered structure, as regarded to those obtained in alkali precipitation medium.

The solids were recovered in both cases by centrifugation at $4000 \mathrm{rpm}$, washed several times with ultrapure water, dried at $353 \mathrm{~K}$, then calcined $4 \mathrm{~h}$ at $500^{\circ} \mathrm{C}$ with a heating rate of $1^{\circ} \mathrm{min}^{-1}$, then cooled down spontaneously. The samples were labeled as with $\mathrm{ZnO}-\mathrm{NaOH}$ and $\mathrm{ZnO}$-Urea.

The characterization of the solids was performed by X-ray diffraction, IR spectroscopy, scanning electron microscopy (SEM), and BET nitrogen adsorption. The XRD patterns were obtained on a Shimadzu D6000 machine, in the range of $5-70^{\circ}$, using $\mathrm{CuK} \alpha$ radiation $(\lambda=1.5406 \AA)$, in steps of $0.05^{\circ}$. The IR spectra were collected on an ABB MB 3000 apparatus. The scanning electron microscopy (SEM) was used to show the morphology of the synthesized solids; a SEM Tescan VEGA II LSH was used in this respect.

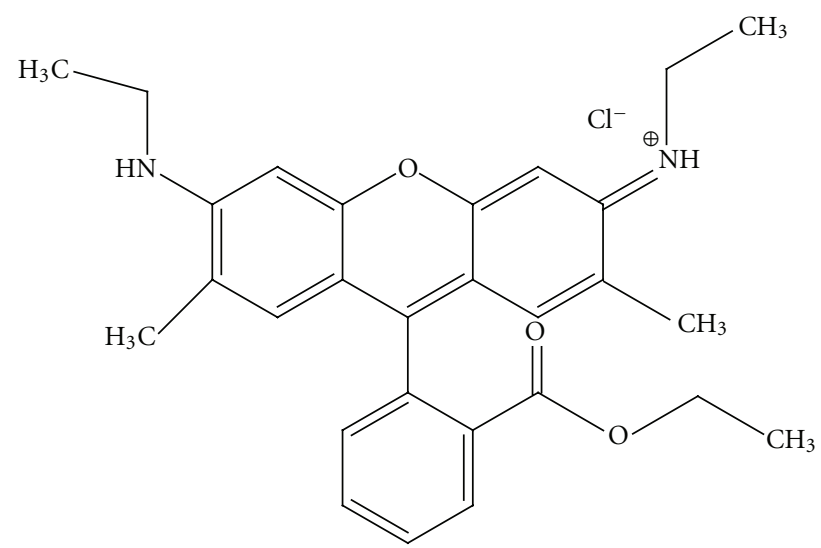

Figure 1: Chemical structure of R_6G.

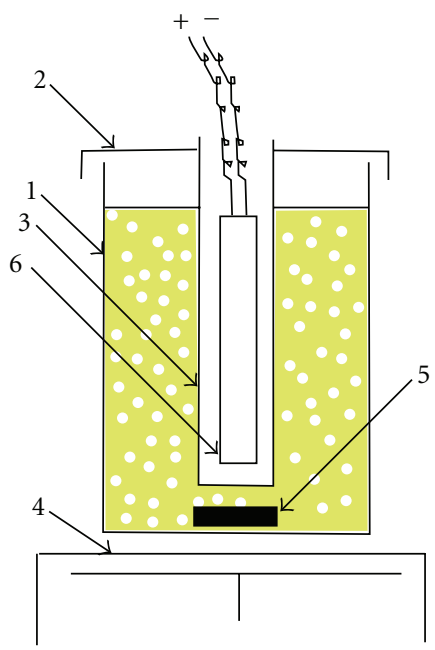

(1) Glass reactor

(2) Pierced cap

(3) Quartz tube

(4) Magnetic range

(5) Magnetic agitator

(6) UV lamp

Black cover

FIGURE 2: Experimental setup for the photocatalytic degradation.

The photocatalytic activities of both synthesized $\mathrm{ZnO}$ samples were studied for the photodegradation of R_6G dye $\left(\mathrm{C}_{28} \mathrm{H}_{31} \mathrm{~N}_{2} \mathrm{O}_{3} \mathrm{Cl}\right)$; the formula is presented in Figure 1 .

The photocatalytic degradation was performed using a cylindrical glass reactor (Figure 2), accommodating a central quartz tube in which an Osram UV-A lamp of $9 \mathrm{~W}$ (wavelength range $350-400 \mathrm{~nm}$, maximum at $370 \mathrm{~nm}$ ) is placed to irradiate the dye solution. At the bottom of the reactor, a magnetic range assures the homogenization. The experiments were performed on samples of $300 \mathrm{~mL}$ aqueous solutions of dye prepared with ultrapure water. The $\mathrm{pH}$ value was set using sulfuric acid $0.1 \mathrm{M}$ or natrium hydroxide $0.1 \mathrm{M}$. The photocatalyst powder was dispersed in the dye solution, magnetically stirred for 30 minutes in dark, in order to enable establishing the adsorption/desorption equilibrium, then the lamp was turned on. Samples of $5 \mathrm{~mL}$ suspension were taken 


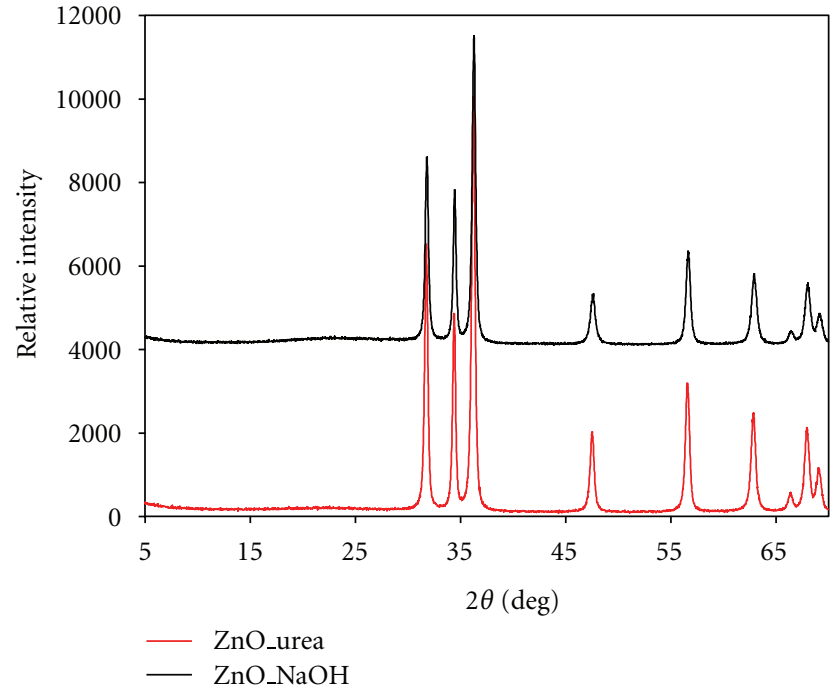

Figure 3: XRD pattern of $\mathrm{ZnO}$ samples.

at specific time intervals, filtered immediately to separate completely the catalyst particles, and measured to determine the remaining dye concentration. Zero time reading was considered the moment when the lamp was turned on.

The dye concentration was measured by UV-vis spectroscopy, using a Shimadzu UV-1700 spectrophotometer; the UV-vis spectrum of R_6G displays a net maximum at $530 \mathrm{~nm}$. An initial calibration was performed to check the extinction-concentration linearity and to ease the calculation of the concentration value by simple reading of the extinction for the dye solutions exposed to UV and/or contacted in dark with $\mathrm{ZnO}$.

The photocatalytic tests were performed in ambient air. The $\mathrm{pH}$ values were monitored using a Microprocessor WTW pH $95 \mathrm{pH}$ Meter. A scheme of the experimental setup is displayed in Figure 2.

The decolorization and photocatalytic degradation efficiency were calculated using the following:

$$
\text { Dye_removal }(\%)=\frac{C_{0}-C_{t}}{C_{0}} \times 100,
$$

where $C_{0}$ and $C_{t}$ are the initial and $t$ is time concentrations of R_6G.

\section{Results and Discussions}

3.1. Characterization of the Photocatalyst. The XRD patterns of the samples $\mathrm{ZnO}-\mathrm{NaOH}$ and $\mathrm{ZnO}$-urea, presented in Figure 3, indicate well-crystallized solids, exhibiting the main peaks due to zinc oxide phase, as filed in JCPDS: 897102 [20] and no impurity phases. The peaks are somehow sharper and higher for the sample obtained with urea, indicating a more uniform and better-crystallized solid.

The XRD pattern also allowed calculating the medium crystallite size using Debye-Scherrer equation. The particle medium size, considering the factor $K=0.94$, gave values of $21.5 \mathrm{~nm}$ for the sample $\mathrm{ZnO}$-urea and $14.4 \mathrm{~nm}$ for

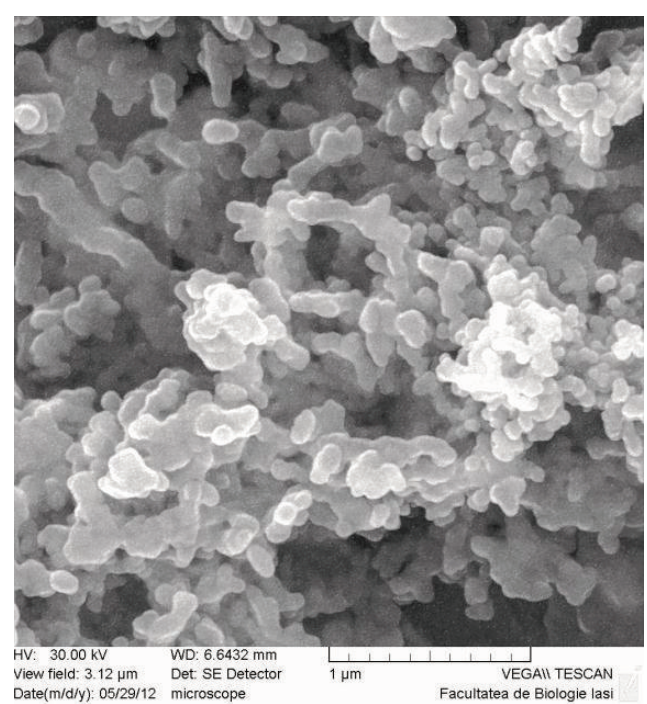

(a)

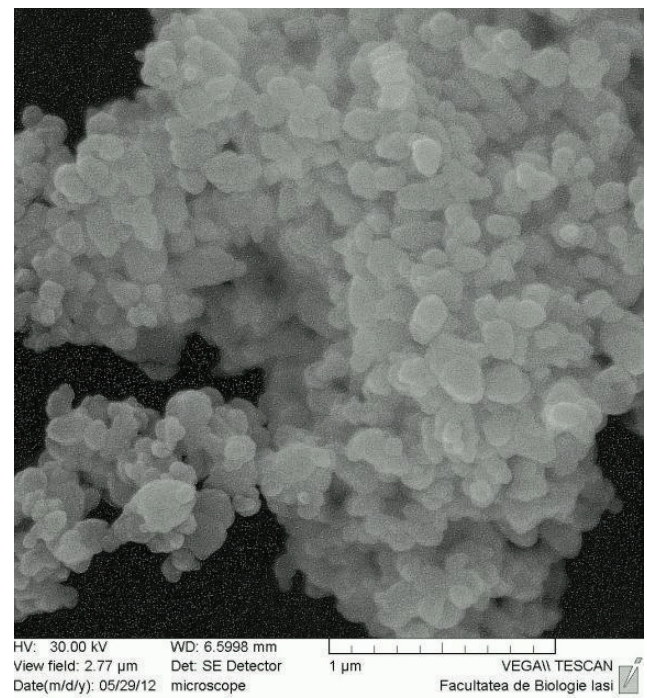

(b)

Figure 4: SEM images of $\mathrm{ZnO}$-urea (a) and $\mathrm{ZnO}-\mathrm{NaOH}$ (b).

$\mathrm{ZnO}-\mathrm{NaOH}$. These particle sizes represent the dimensions of the primary particles, which associate in groups of several hundreds of nanometers, as shown on the SEM images (Figure 4). The grouping of the particles keeps a relatively uniform aspect of the bulk powder.

The agglomerations of $\mathrm{ZnO}$-urea particles are almost spherical in shape and still keep a big free volume fraction in between, which is beneficial for the organic diffusion to the solid surface during the adsorption step. The $\mathrm{ZnO}-\mathrm{NaOH}$ sample consists of grain associations with more planar shape and have the tendency to agglomerate very tightly, offering a smaller interparticle free space.

The IR transmission spectra of our samples were compared with those of a commercial zinc oxide, see Figure 5.

The spectra for the samples synthesized in our laboratory are quite similar and in line with the literature data [21]; only small differences in peaks intensities are noticed for 


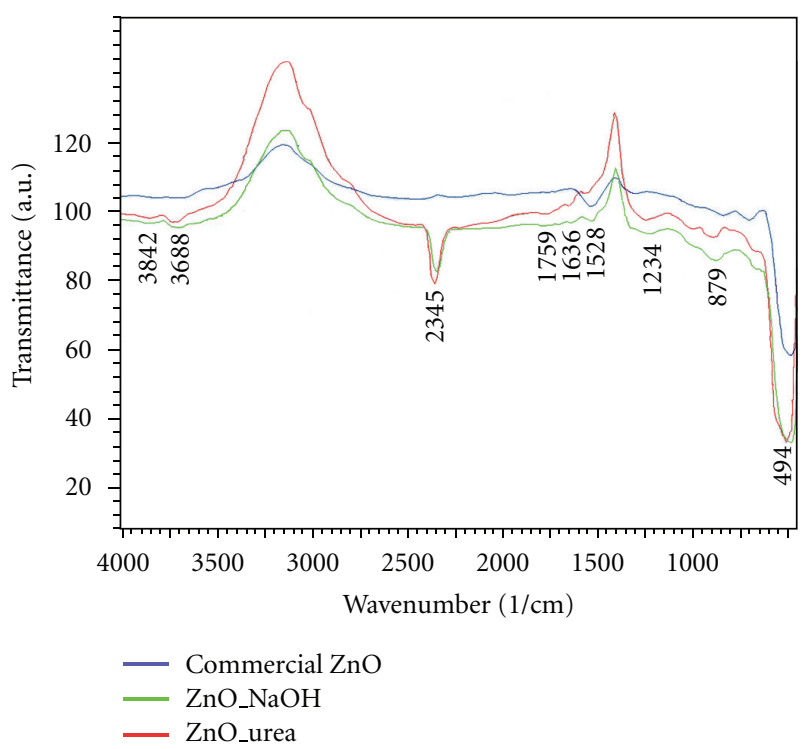

FIGURE 5: IR spectra of zinc oxide samples.

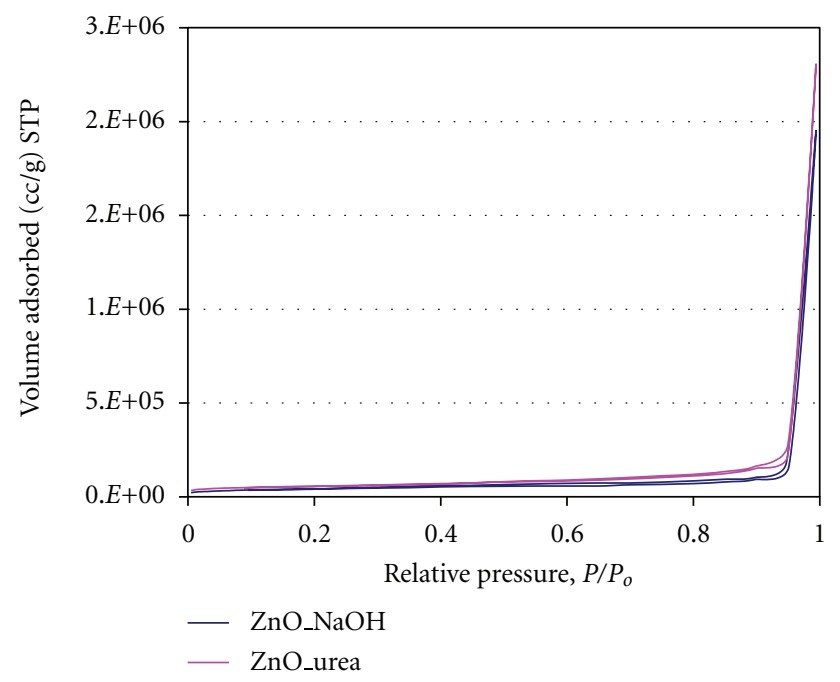

FIgURE 6: BET analysis results for $\mathrm{ZnO}$.

our two samples. The peaks around $3600 \mathrm{~cm}^{-1}$ indicate the presence of $\mathrm{OH}$ groups derived from water adsorption [22], while the one at $1636 \mathrm{~cm}^{-1}$ is due to the characteristic $\mathrm{H}_{2} \mathrm{O}$ scissoring mode. The peak from $2345 \mathrm{~cm}^{-1}$ is due to the $\mathrm{CO}_{2}$ adsorption on the basic sites of $\mathrm{ZnO}$ [23] and is missing in the commercial sample.

The BET analysis allowed the determination of the BETspecific surface areas, found to be $17.3 \mathrm{~m}^{2} \mathrm{~g}^{-1}$ for $\mathrm{ZnO}$-urea and, respectively, $13.04 \mathrm{~m}^{2} \mathrm{~g}^{-1}$ for the $\mathrm{ZnO}-\mathrm{NaOH}$ sample. The slow precipitation leads to higher specific surface areas, as expected. The isotherms of type 3 according to IUPAC, indicates low porosity solids, with a very narrow hysteresis loop. No significant internal porosity is found on these samples, see Figure 6.

3.2. Photocatalytic Experiments. Three parameters were considered important for dye degradation process, namely, the

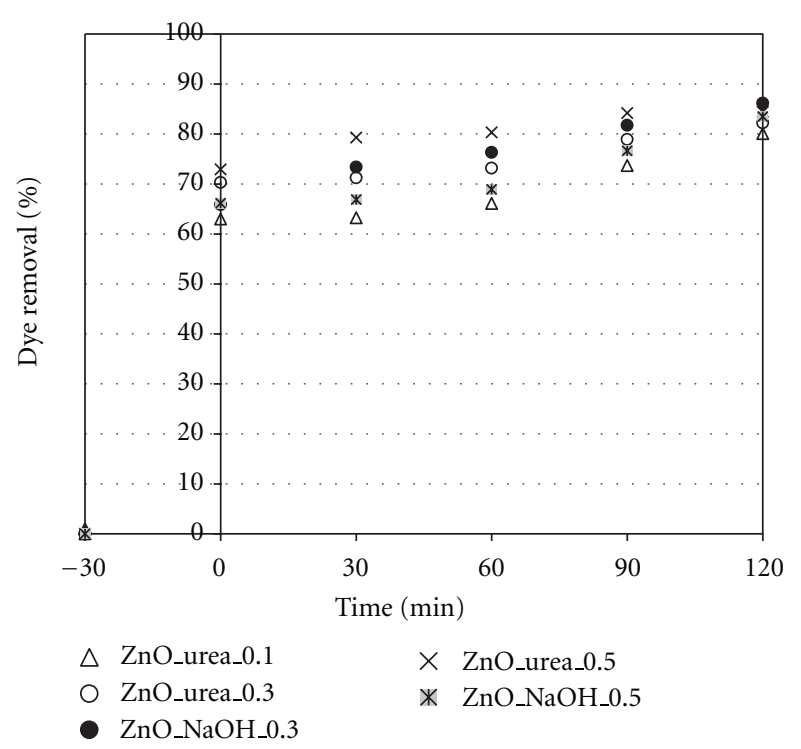

FIGURE 7: The influence of catalyst concentration on R_6G decolorization ( $\mathrm{pH}=10,50 \mathrm{ppm}$ initial dye concentration).

photocatalyst concentration, the $\mathrm{pH}$ value, and the initial dye concentration. In the parametric study, two of the abovementioned factors were kept constant and the third was varied, in order to define their individual and simultaneous influence on the process. The comparison between our samples and titanium dioxide P-25 was made, in some cases, by performing selected experiments in similar conditions.

3.2.1. Influence of Catalyst Concentration. This series of experiments was performed at a constant $\mathrm{pH}=10$ value, working with an initial concentration of R_6G of $50 \mathrm{ppm}$. We used three concentrations of solid photocatalyst: $0.1,0.3$, and $0.5 \mathrm{~g}$ photocatalyst per liter of dye solution. A blank probe (irradiation with no catalyst) gave very low degrees of decolorizing, so we considered negligible the contribution of the radiation alone to decompose $\mathrm{R} \_6 \mathrm{G}$, in the time duration involved in the experiments; similar behavior for rhodamine B has been communicated by Fan et al., [24], Natarajan et al. [25], and Chen et al. [26]. The removal degree in time is displayed in Figure 7.

For all the tested photocatalyst samples, the same characteristic for the removal of R_6G is noticed. They strongly adsorb the dye in the equilibrium period of 30 minutes before the exposure to UV light; more than $60 \%$ of the dye is removed from the solution in all the tested mixtures. The photocatalytic reaction follows a slow increasing slope. The values of the total removal degree are similar for both samples, over $80 \%$ in 2 hours of irradiation. Since the removal degree of the dye on the photocatalyst in the medium containing $0.3 \mathrm{~g}$ catalyst per liter of dye solution is very close to the ones in the system with $0.5 \mathrm{~g}$ catalyst, we admit from this point forward the $0.3 \mathrm{~g} / \mathrm{L}$ as the optimal concentration value.

3.2.2. The Influence of the Reaction $p H$. In order to investigate the influence of the $\mathrm{pH}$ role of the reaction medium on R_6G 


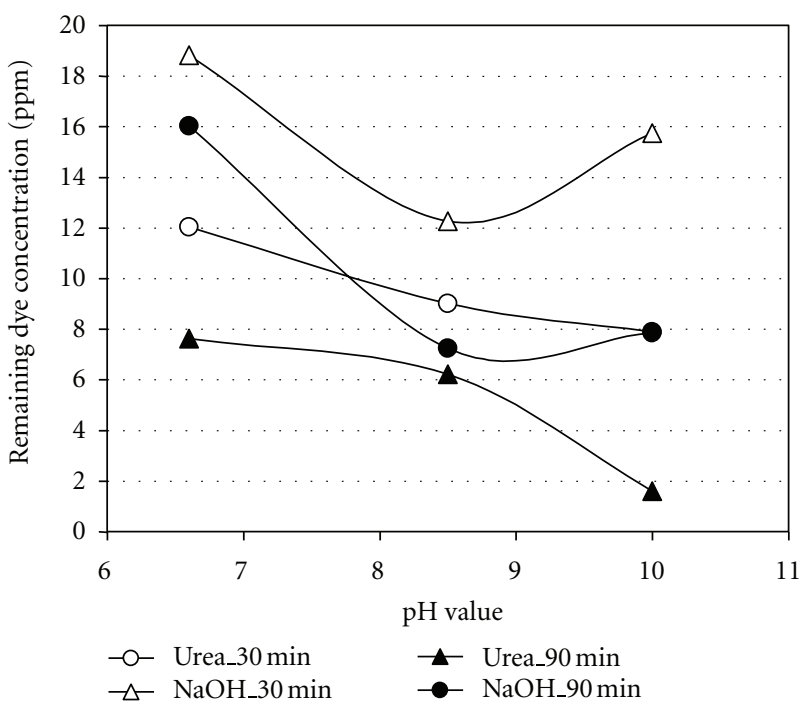

Figure 8: The pH influence on R_6G decolorizing after 30 and 90 minutes of photoreaction $(0.3 \mathrm{~g} / \mathrm{L}$ catalyst, $30 \mathrm{ppm}$ pf dye initially).

decolorizing, this series of experiments was performed using $0.3 \mathrm{~g} / \mathrm{L}$ catalyst, at $\mathrm{pH}$ values of $6.6,8.5$, and 10 . The initial R_6G concentration in these experiments was $30 \mathrm{ppm}$. The dye removal in these conditions is presented in Figure 8.

The differences in the degree of dye removal at the mentioned $\mathrm{pH}$ values are interesting to comment. The high values of the $\mathrm{pH}$ are favorable on dye degradation on $\mathrm{ZnO}$ urea sample at both mentioned irradiation durations, 30 and 90 minutes. On the $\mathrm{ZnO}-\mathrm{NaOH}$ sample, an optimum value of 8.5 for the reaction run can be defined at the considered time values. The dye removal degree reaches $98 \%$ on $\mathrm{ZnO}$ Urea at $\mathrm{pH}=10$ in 90 minutes.

This somehow unexpected behavior determined us to investigate the dye removal by measuring the remaining concentrations at intermediate time values between up to 120 minutes of the photocatalytic reaction, Figure 9.

The evolution of the dye removal in time follows a special dynamic. A strong removal degree by adsorption is noticed during the equilibrium stage before the irradiation, followed by the increase of the dye concentration in the beginning of the photocatalysis step. In some cases this behavior repeats several times, see the curve for $\mathrm{ZnO}-\mathrm{NaOH}$ at $\mathrm{pH}=8.5$. As will be shown in the next paragraph, the phenomenon is not observed if the initial R_6G concentration is low (5 ppm). The explanation for this behavior could be the massive adsorption of the dye on $\mathrm{ZnO}$. The R_6G molecules are adsorbed on the functional groups of $\mathrm{ZnO}$ (most probably, $\mathrm{OH}$ groups, able to interact with the amino and ammonium groups from the structure of $\mathrm{R}_{-} 6 \mathrm{G}$ ) and they allow the subsequent adsorption of the incoming R_6G molecules, most probably by forming "multilayers," since the value of the specific surface area of the solid after the adsorption step does not change significantly $\left(17 \mathrm{~m}^{2} \mathrm{~g}^{-1}\right.$ for the $\mathrm{ZnO}$ Urea sample after the adsorption, compared to $17.3 \mathrm{~m}^{2} \mathrm{~g}^{-1}$ of the initial sample). When the photodegradation begins, the first layer of adsorbed molecules on the photocatalyst surface

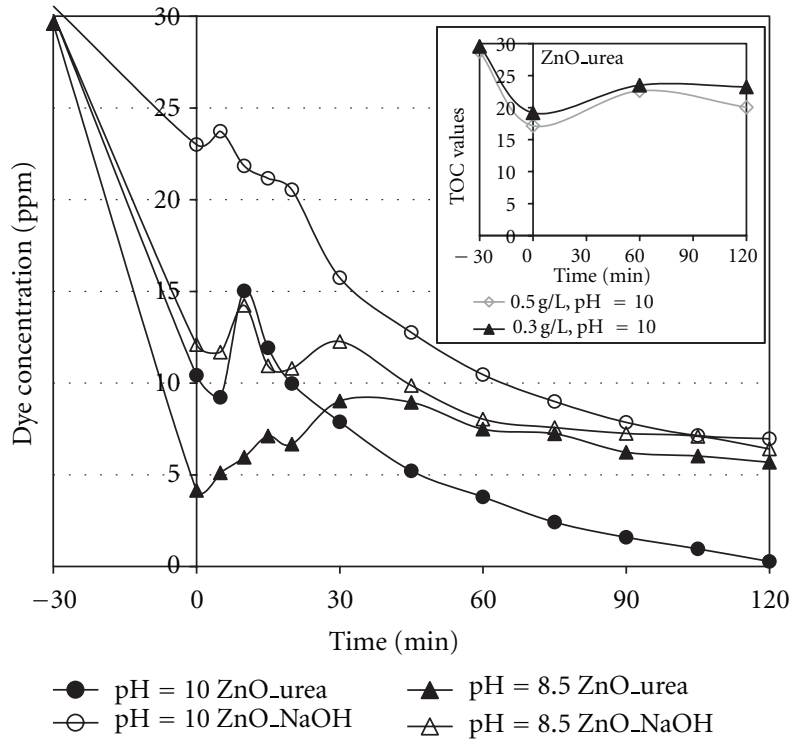

FIGURE 9: R_6G concentration profile in time $(0.3 \mathrm{~g} / \mathrm{L}$ photocatalyst, $30 \mathrm{ppm} / \mathrm{L}$ dye) and TOC values for $\mathrm{ZnO}$-urea sample, at $\mathrm{pH}=10$ and two photocatalyst concentrations.

is destroyed by the photodegradation of several molecules. The other molecules stacked on them are mobilized to the solution and the concentration of the dye increases. They are subsequently readsorbed and finally photodegraded. This statement is further confirmed by the TOC values (inlet Figure 9), showing that the mineralization degree reaches only $20 \%$ in 2 hours of photocatalytic process. The chromophore groups were totally destroyed during this time; the behavior is similar to that observed by Chen et al. [27].

3.2.3. The Influence of Dye Concentration. In order to study influence of the dye concentration on the degradation process, the $\mathrm{pH}$ value was kept at 8.5 and the catalyst concentration at $0.3 \mathrm{~g} / \mathrm{L}$, while the dye concentrations for the tests were 5, 30, and $50 \mathrm{ppm}$, see Figure 10 .

An almost constant increase of the R-6G removal degree occurs at the low value of $5 \mathrm{ppm}$ dye on the sample $\mathrm{ZnO}$ Urea. In this case, after 2 hours of irradiation the removal of the organic is practically total. The other solid has a similar but less performant behavior. At the higher concentrations values, the removal occurs in 2 hours at degrees of around $80 \%$ for the initial value of $30 \mathrm{ppm}$ and of $70-75 \%$ for the solution containing $50 \mathrm{ppm}$ of R_6G. This group of experiments proves a better net behavior of the $\mathrm{ZnO}$-urea sample in comparison with $\mathrm{ZnO}-\mathrm{NaOH}$.

3.2.4. Comparison with $\mathrm{TiO}_{2}$ Degussa P-25. The use of other photocatalysts is interesting especially when the widely used and very versatile P-25 Titania cannot be used. Titania is stable and active in slightly acidic conditions, but occur important structural degradations at alkaline $\mathrm{pH}$ values, while $\mathrm{ZnO}$ is only stable in neutral to alkaline medium. 


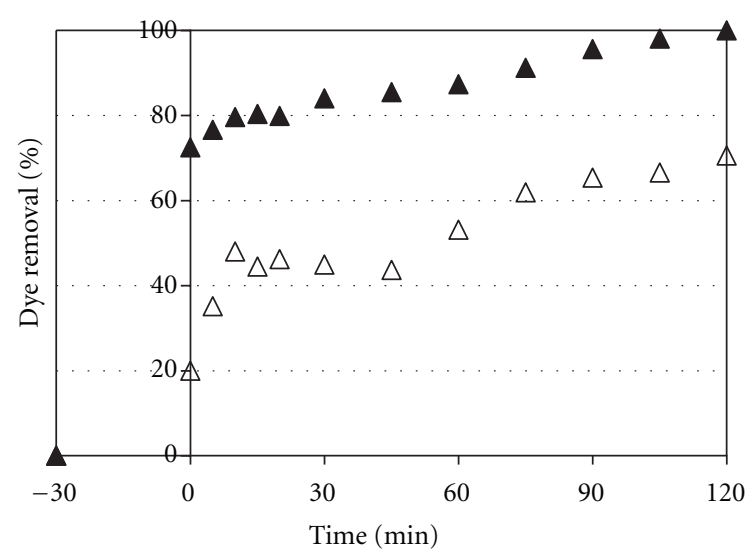

$\Delta$ ZnO_urea 5 ppm

$\triangle \mathrm{ZnO} \_\mathrm{NaOH}$-5 ppm

(a)

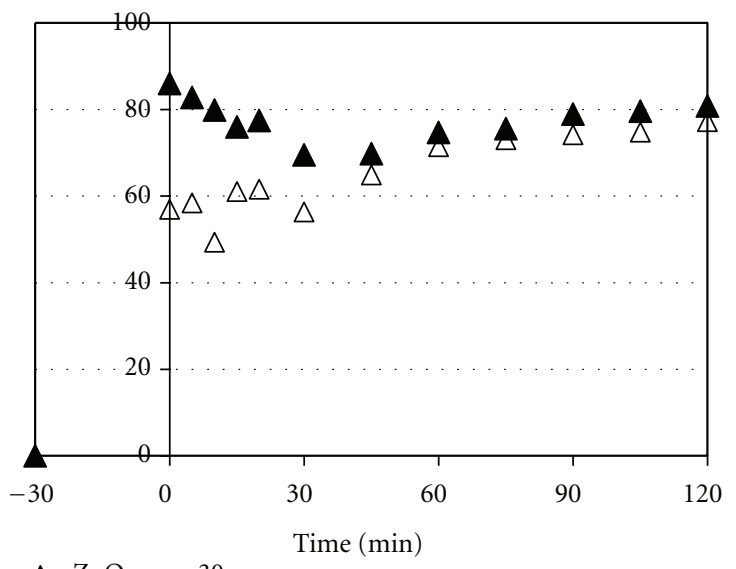

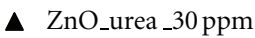

$\triangle$ ZnO_NaOH_30 ppm

(b)

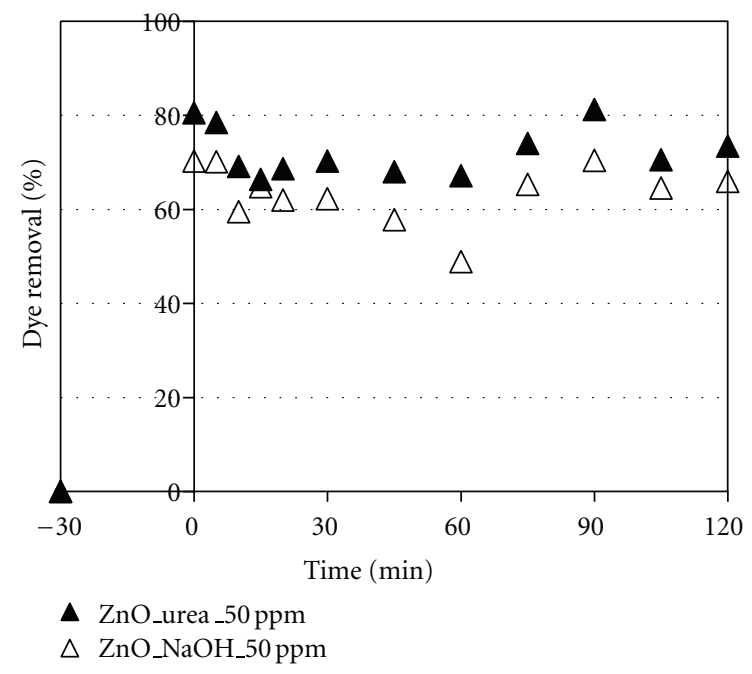

(c)

Figure 10: The dye removal in time at 5, 30, and 50 ppm of R_6G $(0.3 \mathrm{~g}$ photocatalyst/L, $\mathrm{pH}=8.5)$.

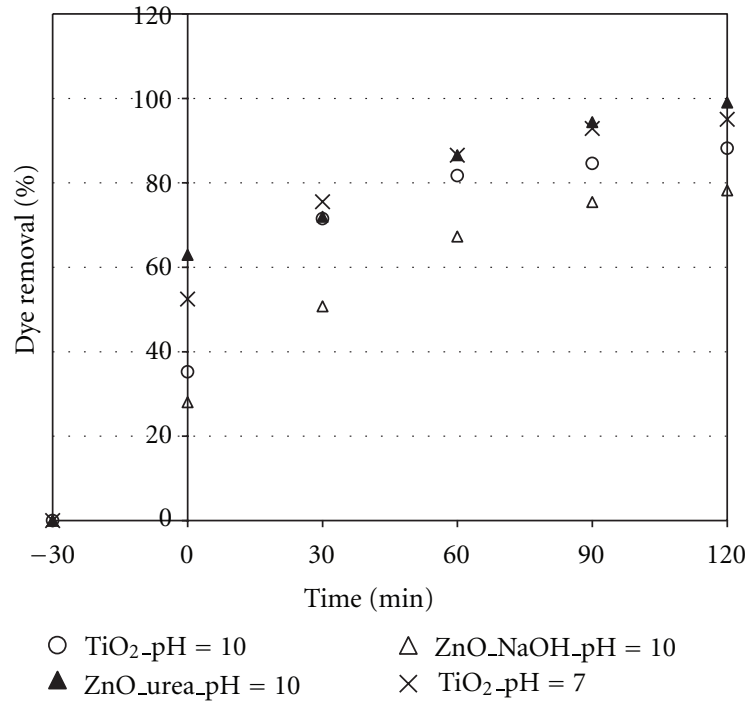

Figure 11: Comparison between R_6G removal on $\mathrm{ZnO}$ and $\mathrm{TiO}_{2}$.

In order to compare the performance in the photoreaction of our $\mathrm{ZnO}$ samples with the results obtained on Titania, we performed two experiments on both $\mathrm{ZnO}$ samples at $\mathrm{pH}=10$ and on $\mathrm{P}-25$ at $\mathrm{pH}$ values of 7 and 10 , using an initial solution of $30 \mathrm{ppm}$ R_6G at a photocatalyst concentration of $0.3 \mathrm{~g} / \mathrm{L}$, Figure 11.

The dye removal on $\mathrm{TiO}_{2}$ indicates its different adsorptive behavior in function of the $\mathrm{pH}$ value. There is a clear higher adsorption degree at $\mathrm{pH}=7$ than at $\mathrm{pH}=10$, but the photocatalytic reaction brings quite similar removal degrees for both $\mathrm{pH}$ values, over $80 \%$ for both cases.

The performance of the $\mathrm{ZnO}$-urea is closely similar to that on P-25. Since the stability at high $\mathrm{pH}$ values is better for $\mathrm{ZnO}$ than for $\mathrm{TiO}_{2}$, our photocatalyst could be an alternative to the well-known P-25, for the photocatalytic reactions performed in basic solutions for rebel compounds decomposition.

In Table 1 are presented some selected results comparing the photocatalytic activity of $\mathrm{ZnO}$ samples and $\mathrm{TiO}_{2}$, at $\mathrm{pH}$ values ensuring the stability of the samples.

The values show that the activity of $\mathrm{ZnO}$-urea sample at alkaline $\mathrm{pH}$ is close to that of $\mathrm{TiO}_{2}$ at $\mathrm{pH}$ values lower with about 3 units.

\section{Conclusions}

The zinc oxide prepared by zinc nitrate precipitation in urea medium, followed by calcination at $500^{\circ} \mathrm{C}$, led to the obtaining of a zinc oxide sample with high capabilities of R_6G removal from slightly basic aqueous media. The study of parameters influencing the decolorizing process allowed us to find the operating conditions for achieving the highest dye removal rate: $\mathrm{pH}$ values over 8.5 , up to 10 ; catalyst concentration $0.3 \mathrm{~g} / \mathrm{L}$; initial dye concentrations higher than $30 \mathrm{ppm}$. A strong initial adsorption is noticed on $\mathrm{ZnO}$ samples, followed by a slow photocatalytic reaction 
TABLE 1: Selected results on photocatalytic activities of the $\mathrm{ZnO}$ and $\mathrm{TiO}_{2}$ samples.

\begin{tabular}{|c|c|c|c|c|c|c|}
\hline & $\begin{array}{c}\text { ZnO_urea } \\
90 \text { min } \\
\text { pH } 8.5\end{array}$ & $\begin{array}{c}\mathrm{ZnO}{ }_{2} \mathrm{NaOH} \\
90 \mathrm{~min} \\
\mathrm{pH} 8.5\end{array}$ & $\begin{array}{c}\text { ZnO_urea } \\
90 \text { min } \\
\text { pH } 10\end{array}$ & $\begin{array}{c}\mathrm{ZnO}{ }^{9} \mathrm{NaOH} \\
\text { pH } 10\end{array}$ & $\begin{array}{c}\mathrm{TiO}_{2} \\
90 \mathrm{~min} \\
\text { pH } 3.7\end{array}$ & $\begin{array}{c}\mathrm{TiO}_{2} \\
90 \mathrm{~min} \\
\text { pH } 5.5\end{array}$ \\
\hline $\begin{array}{l}\text { R_6G } \\
30 \text { ppm }\end{array}$ & 74.70 & 71.41 & 94.34 & 75.42 & 86.02 & 92.43 \\
\hline $\begin{array}{l}\text { R_6G } \\
50 \mathrm{ppm}\end{array}$ & 67.10 & 48.86 & 85.19 & - & - & 84.68 \\
\hline
\end{tabular}

on $\mathrm{ZnO}$. The global performance in terms of dye removal is comparable with that obtained on P-25 Titania, known as the most typical and widely applied photocatalyst.

\section{Acknowledgments}

The authors are grateful for the partial support of this work by the Bilateral Research Grant Romania-Greece no. 576/2012 financed in Romania by ANCS/UEFISCDI and in Greece by GSRT from the Greek Ministry of Education, Lifelong Learning and Religious Affairs.

\section{References}

[1] S. Malato, J. Blanco, A. Vidal, and C. Richter, "Photocatalysis with solar energy at a pilot-plant scale: an overview," Applied Catalysis B, vol. 37, no. 1, pp. 1-15, 2002.

[2] M. N. Chong, B. Jin, C. W. K. Chow, and C. Saint, "Recent developments in photocatalytic water treatment technology: a review," Water Research, vol. 44, no. 10, pp. 2997-3027, 2010.

[3] A. Di Paola, E. García-López, G. Marcì, and L. Palmisano, "A survey of photocatalytic materials for environmental remediation," Journal of Hazardous Materials, vol. 211-212, pp. 3-29, 2012.

[4] I. Oller, S. Malato, and J. A. Sánchez-Pérez, "Combination of advanced oxidation processes and biological treatments for wastewater decontamination-a review," Science of the Total Environment, vol. 409, pp. 4141-4166, 2011.

[5] K. Nakata and A. Fujishima, " $\mathrm{TiO}_{2}$ photocatalysis: design and applications-review article," Journal of Photochemistry and Photobiology C, vol. 13, no. 3, pp. 169-189, 2012.

[6] K. Hashimoto, H. Irie, and A. Fujishima, " $\mathrm{TiO}_{2}$ photocatalysis: a historical overview and future prospects," AAPPS Bulletin, vol. 17, no. 6, 2007.

[7] A. Fujishima, T. N. Rao, and D. A. Tryk, "Titanium dioxide photocatalysis," Journal of Photochemistry and Photobiology C, vol. 1, no. 1, pp. 1-21, 2000.

[8] S. Anandan, Y. Ikuma, and V. Murugesan, "Highly active rareearth-metal la-doped photocatalysts: fabrication, characterization, and their photocatalytic activity," International Journal of Photoenergy, vol. 2012, Article ID 921412, 10 pages, 2012.

[9] C. . Tian, Q. Zhang, A. Wu et al., "Cost-effective large-scale synthesis of $\mathrm{ZnO}$ photocatalyst with excellent performance for dye photodegradation," Chemical Communications, vol. 48, pp. 2858-2860, 2012.

[10] M. N. Ghazzala, H. Kebaili, M. Joseph et al., "Photocatalytic degradation of Rhodamine $6 \mathrm{G}$ on mesoporous titania films: combined effect of texture and dye aggregation forms," Applied Catalysis B, vol. 115-116, pp. 276-284, 2012.

[11] C. Guo, J. Xu, Y. He, Y. Zhang, and Y. Wang, "Photodegradation of rhodamine B and methyl orange over one-dimensional
$\mathrm{TiO}_{2}$ catalysts under simulated solar irradiation," Applied Surface Science, vol. 257, no. 8, pp. 3798-3803, 2011.

[12] X. Yang, L. Xu, X. Yu, and Y. Guo, "One-step preparation of silver and indium oxide co-doped $\mathrm{TiO}_{2}$ photocatalyst for the degradation of rhodamine B," Catalysis Communications, vol. 9, no. 6, pp. 1224-1229, 2008.

[13] D. Arsene, C. P. Musteret, C. Catrinescu, P. Apopei, G. Barjoveanu, and C. Teodosiu, "Combined oxidation and ultrafiltration processes for the removal of priority organic pollutants from wastewaters," Environmental Engineering and Management Journal, vol. 10, no. 12, pp. 1967-1976, 2011.

[14] T. S. Natarajan, M. Thomas, K. Natarajan, H. C. Bajaj, and R. J. Tayade, "Study on UV-LED/ $/ \mathrm{TiO}_{2}$ process for degradation of Rhodamine B dye," Chemical Engineering Journal, vol. 169, no. 1-3, pp. 126-134, 2011.

[15] J. Zhang, S. Yan, L. Fu et al., "Photocatalytic degradation of rhodamine $\mathrm{B}$ on anatase, rutile, and brookite $\mathrm{TiO}_{2}$," Chinese Journal of Catalysis, vol. 32, no. 6, pp. 983-991, 2011.

[16] J. Y. Li, W. H. Ma, P. X. Lei, and J. C. Zhao, "Detection of intermediates in the $\mathrm{TiO}_{2}$-assisted photodegradation of Rhodamine B under visible light irradiation," Journal of Environmental Sciences, vol. 19, no. 7, pp. 892-896, 2007.

[17] S. M. . Soosen, B. Lekshmi, and K. C. George, "Optical properties of $\mathrm{ZnO}$ nanoparticles," SB Academic Review, vol. 16, no. 2, pp. 57-65, 2009.

[18] U. Costantino, F. Marmottini, M. Nocchetti, and R. Vivani, "New synthetic routes to hydrotalcite-like compoundscharacterisation and properties of the obtained materials," European Journal of Inorganic Chemistry, no. 10, pp. 14391446, 1998.

[19] K. Okamoto, N. Iyi, and T. Sasaki, "The urea method for the direct synthesis of $\mathrm{ZnAl}$ layered double hydroxides with nitrate as the interlayer anion," Applied Clay Science, vol. 37, pp. 2331, 2007.

[20] B. S. Barros, R. Barbosa, N. R. Dos Santos, T. S. Barros, and M. A. Souza, "Synthesis and $\mathrm{x}$-ray diffraction characterization of nanocrystalline $\mathrm{ZnO}$ obtained by Pechini method," Inorganic Materials, vol. 42, no. 12, pp. 1348-1351, 2006.

[21] http://webbook.nist.gov/cgi/cbook.cgi?Spec=B6004648\&In$\mathrm{dex}=0 \&$ Type $=$ IR\&Large $=$ on .

[22] H. Noei, H. Qiu, Y. Wang, E. Löffler, C. Wöll, and M. Muhler, "The identification of hydroxyl groups on $\mathrm{ZnO}$ nanoparticles by infrared spectroscopy," Physical Chemistry Chemical Physics, vol. 10, no. 47, pp. 7092-7097, 2008.

[23] G. Pragati, Carbon dioxide adsorption on nanomaterials [Ph.D. dissertation], University of Iowa, 2010, http://ir.uiowa .edu/etd/670.

[24] Y. Fan, G. Chen, D. Li et al., "Highly selective deethylation of rhodamine B on $\mathrm{TiO}_{2}$ prepared in supercritical fluids," International Journal of Photoenergy, vol. 2012, Article ID 173865, 7 pages, 2012.

[25] T. S. Natarajan, M. Thomas, K. Natarajan, H. C. Bajaj, and R. J. Tayade, "Study on UV-LED/ $\mathrm{TiO}_{2}$ process for degradation of 
Rhodamine B dye," Chemical Engineering Journal, vol. 169, no. 1-3, pp. 126-134, 2011.

[26] X. Chen, Z. Xue, Y. Yao, W. Wang, F. Zhu, and C. Hong, "Oxidation degradation of rhodamine $\mathrm{B}$ in aqueous by $\mathrm{UV} / \mathrm{S} 2 \mathrm{O}^{2-}$ treatment system," International Journal of Photoenergy, vol. 2012, Article ID 754691, 5 pages, 2012.

[27] F. Chen, J. Zhao, and H. Hidaka, "Highly selective deethylation of Rhodamine B: adsorption and photooxidation pathways of the dye on the $\mathrm{TiO}_{2} / \mathrm{SiO}_{2}$ composite photocatalyst," International Journal of Photoenergy, vol. 5, no. 4, pp. 209-217, 2003. 


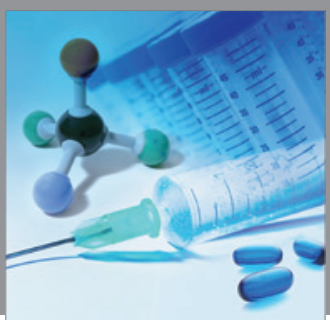

International Journal of

Medicinal Chemistry

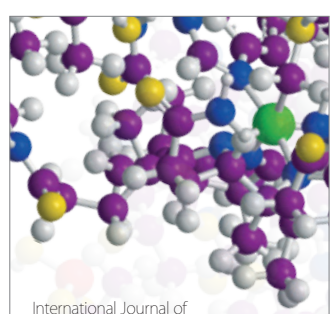

Carbohydrate Chemistry

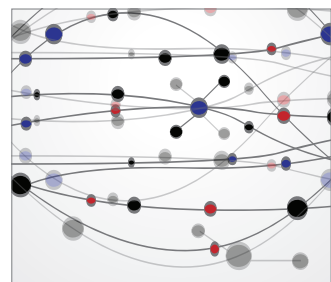

The Scientific World Journal
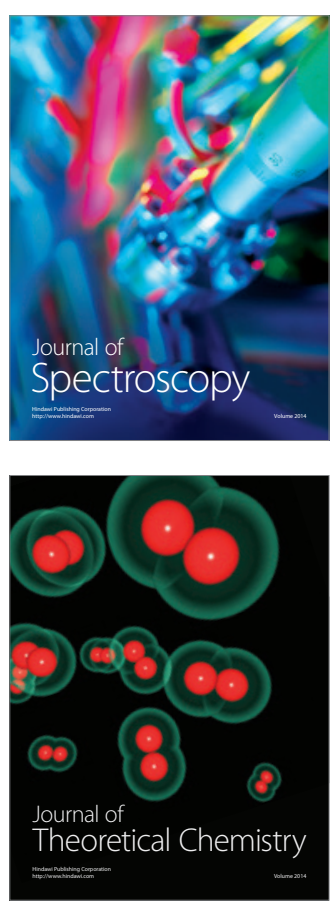
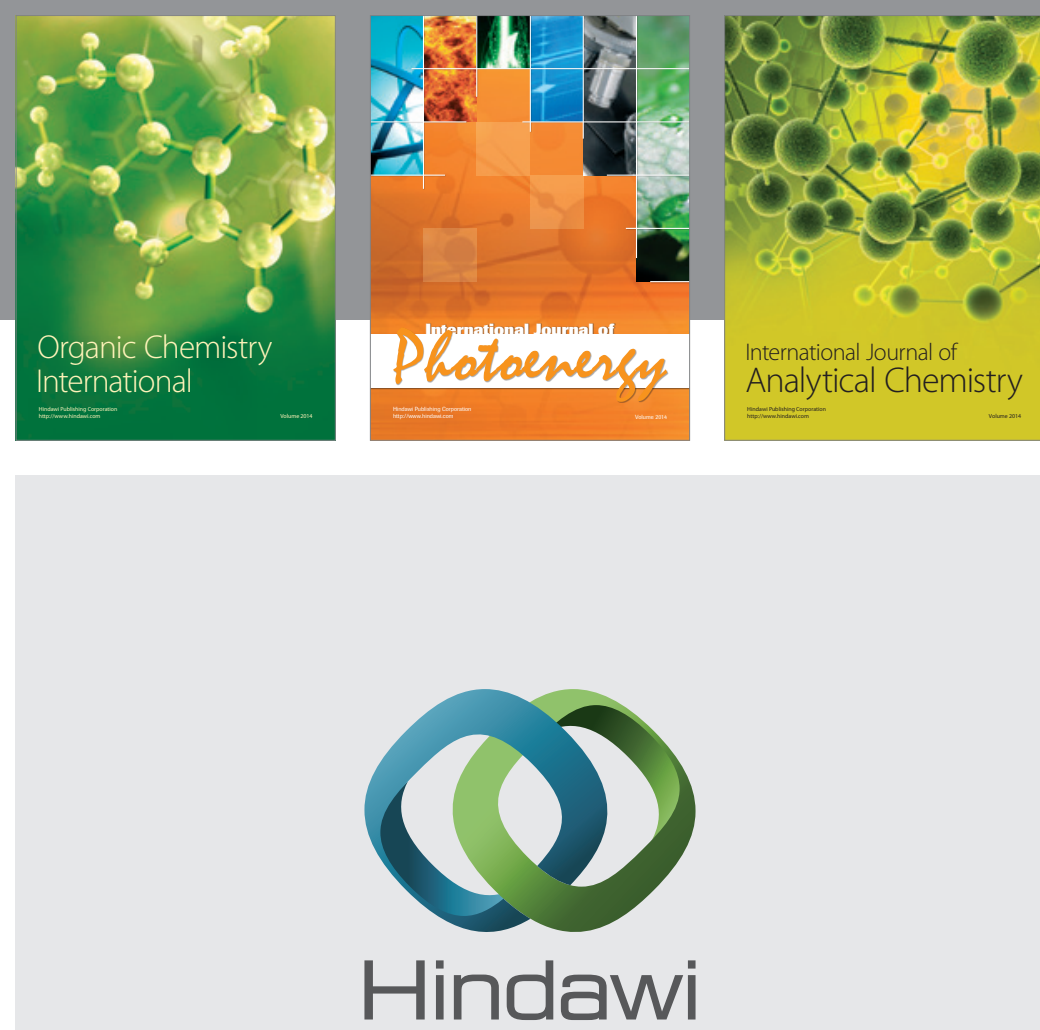

Submit your manuscripts at

http://www.hindawi.com
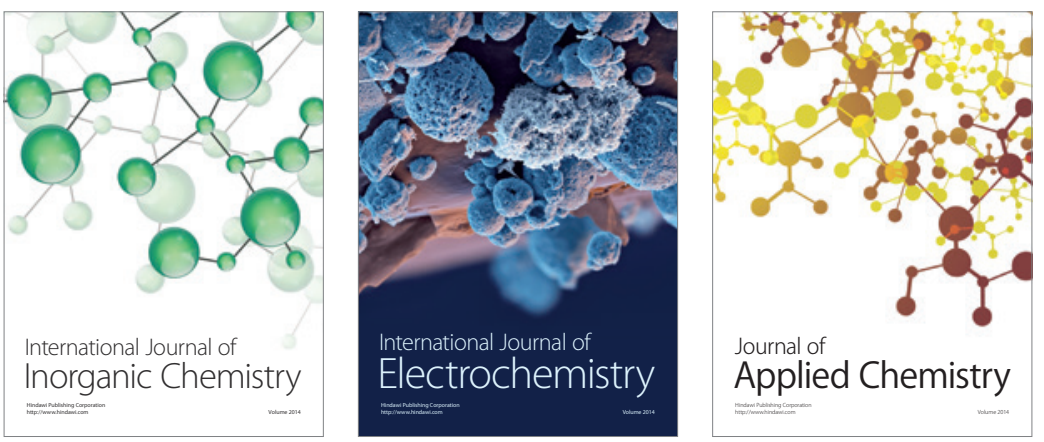

Journal of

Applied Chemistry
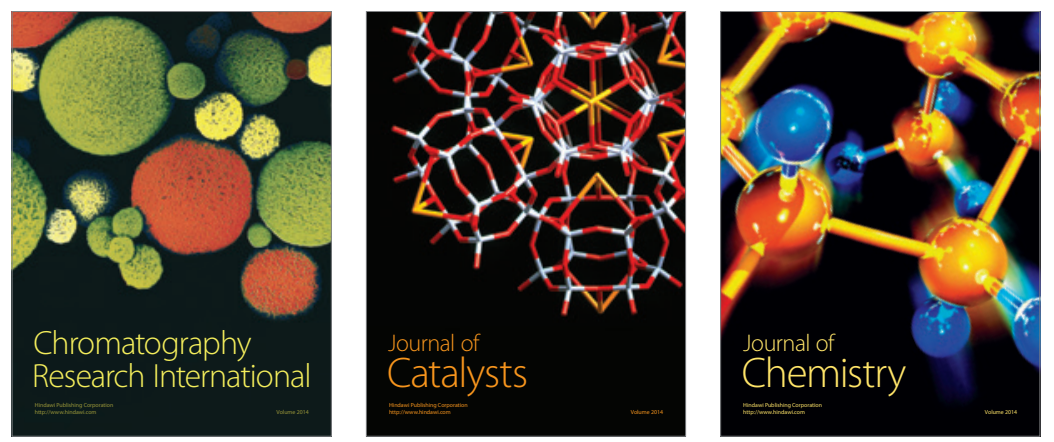
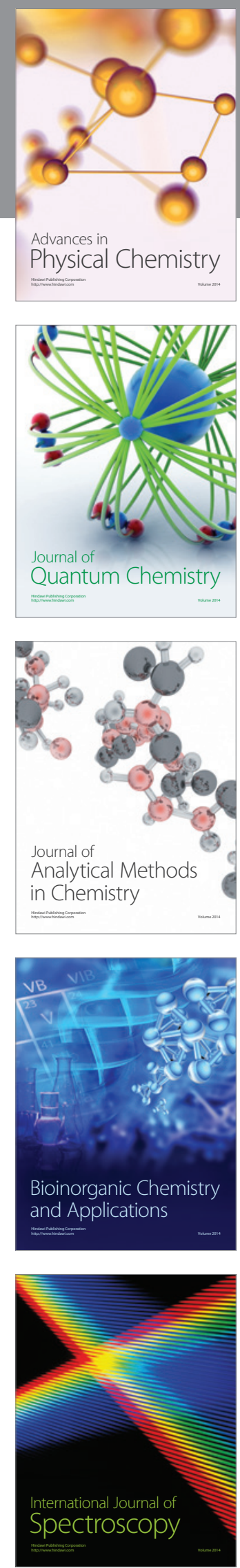